\title{
O ensino de História no Paraná, na década de setenta: práticas de professores*
}

\section{Cláudia Regina Kawka Martins**}

\begin{abstract}
RESUMO
Neste artigo, é ressaltada a importância do resgate da memória de professores nas pesquisas sobre educação e apresenta-se o resultado da pesquisa realizada sobre o ensino de História nos anos setenta, no momento em que a referida disciplina estava diluída na área de Estudos Sociais. O objetivo da pesquisa realizada foi o de analisar como a reforma de ensino de 1971, conhecida como a Lei n. ${ }^{\circ}$ 5692, atingiu o ensino de História paranaense, mais precisamente na cidade de Curitiba e Região Metropolitana, levando em conta, além das fontes escritas - tais como documentos oficiais e currículo -, os testemunhos orais de alguns professores de Estudos Sociais da época. Embora a metodologia utilizada tenha partido tanto de fontes escritas como orais, será dado destaque, neste artigo, à questão da reconstrução da memória das professoras que foram entrevistadas.
\end{abstract}

Palavras chave: ensino de História, práticas de professores, memória

\begin{abstract}
This article underscores the importance of recovering the teacher's memory in the studies concerning education and presents the results of a research performed regarding the teaching of History in the seventies, at a moment when this discipline was diluted in the area of Social Studies. The purpose
\end{abstract}

* Este artigo é parte da dissertação de Mestrado defendida em dezembro de 1999, no curso de Pós-graduação em Educação, Setor de Educação, da Universidade Federal do Paraná, sob orientação da professora Doutora Serlei Maria Fischer Ranzi, intitulada O ensino de História no Paraná, na década de setenta: legislações e práticas.

** Mestre em Educação, professora de História do Colégio Militar de Curitiba. 
of the study was to analyse how the teaching reform of 1971, known as Law n. ${ }^{\circ}$ 5692, affected the teaching of History in the State of Paraná, more specifically in the city of Curitiba and its metropolitan area, taking into account, besides the written sources - such as official documents and curriculum -, the oral testimony of some teachers of Social Studies in that period. Although the applied methodology had developed from both written and oral sources, in this article prominency is given to the question of reconstructing the memory of the interviewed teachers.

Key words: teaching of History, teacher's practice, memory.

\section{Introdução}

Após a reforma de 1971, conhecida como Lei n. ${ }^{\circ}$ 5692, o ensino de História passou por várias mudanças, dentre as quais as modificações nos guias curriculares e o atrelamento à área de Estudos Sociais, em que a História passou a dividir espaço com a Geografia, a Organização Social e Política do Brasil (OSPB) e a Educação Moral e Cívica (EMC).

Para entender o porquê das mudanças no ensino de História na década de setenta, foi preciso analisar o contexto da época, bem como a ação do Estado sobre a educação, o interesse do governo em promover as reformas e qual era o tipo de cidadão que esse Estado pretendia formar.

Não basta, porém, analisar apenas a construção do discurso do Estado e a sua transmissão através das reformas do ensino e das mudanças curriculares. É preciso investigar e analisar a adesão ou a resistência dos professores na aplicação das reformas em sala de aula, na sua prática diária.

Essa relação entre o discurso e a prática é fundamental, pois não se pode reduzir a realidade apenas aos discursos, segundo as novas perspectivas historiográficas. Segundo Antônio NÓVOA (1996, p. 5), um dos objetivos atuais da História da educação é olhar com mais atenção para a internalidade do trabalho escolar, o funcionamento interno das escolas, o desenvolvimento do currículo, a construção do conhecimento escolar, a vida e a experiência dos alunos e professores.

A metodologia usada na pesquisa partiu da utilização tanto de fontes escritas como orais. As fontes escritas de maior relevância para essa pesquisa foram o currículo de Estudos Sociais utilizado na década de setenta, no Paraná, o qual foi publicado em 1976, e os relatórios, discursos de governo e planos 
de implantação da reforma publicados pela então Secretaria da Educação e Cultura do Estado do Paraná.

Além das discussões sobre currículo, uma das partes mais importantes da pesquisa foi calcada nas entrevistas com os professores. Reconhece-se atualmente que existem aspectos da realidade histórica que foram, durante muito tempo, deixados de lado pelos historiadores e que podem ser buscados via fonte oral. Afinal, nem sempre aquilo que já está escrito consegue responder ao que o historiador se propõe a pesquisar. Para tanto, optou-se por fazer o cruzamento das diversas fontes utilizadas, escritas e orais. Como a memória é uma construção e uma seleção do passado, o historiador deve estar sempre atento àquilo que está sendo resgatado através da fonte oral.

\section{A utilização da memória como fonte histórica}

A utilização da história oral como fonte para o historiador é relativamente recente. No Brasil, ela foi introduzida nos anos setenta, porém só nos últimos anos ela tem se expandido mais significativamente. Hoje, os depoimentos e histórias de vida vêm ocupando espaços cada vez maiores nas pesquisas historiográficas e educacionais.

Hoje, a proposta metodológica da história oral é bem aceita e é utilizada por um número cada vez maior de pesquisadores. Ao utilizar-se a metodologia oral, é necessário sempre ter em mente que aquilo que foi dito por um informante não corresponde necessariamente à realidade histórica, pois a memória é essencialmente seletiva. Por isso, as fontes orais têm algumas limitações, daí a necessidade, segundo alguns autores, de se trabalhar juntamente com os registros escritos (GARRIDO, 1992, p. 39). A fonte oral requer, como qualquer outro tipo de fonte, uma aproximação crítica.

Segundo José Carlos MEIHY (1996, p. 49), atualmente, existem três tendências nas pesquisas que se utilizam de fontes orais: a história oral temática, a tradição oral e a história oral de vida. Nesta pesquisa, foi utilizada a história oral temática, pois o objetivo da coleta dos depoimentos foi o de esclarecer um determinado tema; no caso, o ensino de História na década de setenta. Assim, não foi a história de vida dos professores em si que interessava à pesquisa, mas sim os acontecimentos que tiveram alguma relação com o tema estudado. 
Selva FONSECA (1997) afirma que o uso das fontes orais é uma forma de redimensionar os estudos na área da História e da Educação. "As fontes escritas e visuais, em geral, são restritivas, ou escassas, e não permitem registrar certas faces da historicidade das produções, das mudanças, a vida, a ação dos sujeitos produtores. Isto quer dizer que, partindo apenas delas, dimensões importantíssimas do movimento histórico, da produção historiográfica e da história da educação não constituem objeto de pesquisa." (FONSECA, 1997, p. 43)

Devido ao fato de se ter utilizado fontes orais na pesquisa realizada, é importante apresentar algumas discussões sobre memória e História, as quais tiveram início com a obra de Maurice HALBWACHS (1990), A memória coletiva, escrita na década de trinta. Nessa obra, o autor destaca a importância de se resgatar a memória nas pesquisas historiográficas.

HALBWACHS (1990) trouxe para o estudo da memória o conceito de memória coletiva. Para ele, a memória é uma representação do passado que não é do indivíduo apenas, mas desse indivíduo inserido dentro de um grupo familiar e social. "A priori, a memória parece ser um fenômeno individual, algo relativamente íntimo, próprio da pessoa. Mas Maurice Halbwachs, nos anos 20-30, já havia sublinhado que a memória deve ser entendida também, ou sobretudo, como um fenômeno coletivo e social, ou seja, como um fenômeno construído coletivamente [...].” (POLLAK, 1992, p. 201)

A questão da memória enquanto construção foi trabalhada por diversos autores além de HALBWACHS, dentre os quais Michael POLLAK (1992), o qual afirmou que a memória organiza-se em função das preocupações pessoais e políticas do momento. No Brasil, Ecléa BOSI (1983), na sua obra Memória e Sociedade, trabalha com esse conceito de memória construída, baseada nos trabalhos de HALBWACHS e Bergson. Para ela, "lembrar não é reviver, mas refazer, reconstruir, repensar, com imagens e idéias de hoje, as experiências do passado.” (BOSI, 1983, p. 17)

A partir disso, constata-se que a memória é uma representação do passado a partir da visão que se tem do presente e, mais ainda, ela é uma seleção do passado. Como afirma POLLAK (1992, p. 204), "a memória é seletiva, nem tudo fica gravado, nem tudo fica registrado." Devido a isso, o uso da memória enquanto fonte histórica foi por muito tempo criticado. Acreditava-se que ela não possuía a mesma objetividade da fonte escrita, pois prevalecia a versão mais tradicional de documento, aquela do positivismo, que o via como um fato real, como um espelho da realidade histórica, daquilo que realmente aconteceu. Apenas o que estava escrito poderia constituir uma fonte histórica. (MARSON, 1984, p. 51) 
Com a fundação da revista Annales, em 1929, na França, por Marc Bloch e Lucien Febvre, começaram as críticas a essa visão positivista de documento e à História factual. LE GOFF (1990), na obra História e Memória, fala dos problemas atuais por que passa o conceito de História. Uma dessas questões é a crítica à noção de documento e à idéia de fato histórico enquanto uma realidade. Essa crítica surge a partir do momento em que se desenvolve a historiografia: a história da história.

Assim, ocorre hoje um novo interesse pela testemunha. Mas nem sempre foi assim. Como já foi dito, com o positivismo, a história terminava onde começava a memória e não cabia aos historiadores estudar o tempo presente. História era igual a passado. "Só há pouco tempo houve uma inversão: a memória invadiu o campo da história. Daí a obrigação de repensar uma e outra. [...] A memória, até então vista como impura, torna-se objeto de história: passa a haver uma história da memória." (HARTOG, 1990, p. 15) Hoje, as fontes históricas são múltiplas, não apenas aquilo que está escrito.

O importante, portanto, é fazer uma séria crítica às fontes utilizadas, sejam elas escritas ou orais. Afinal, se a memória é socialmente construída, o mesmo ocorre com a documentação escrita.

Assim como a memória foi durante muito tempo negligenciada pelos historiadores, o mesmo ocorreu com o estudo da vida dos professores nas pesquisas educacionais. Só muito recentemente começaram a aparecer pesquisas sobre as vidas dos professores e suas carreiras, fato que coincidiu com o desenvolvimento do método da história oral.

Hoje, já existe no meio historiográfico um reconhecimento da necessidade de se estudar as histórias individuais dos professores. Atualmente existem várias pesquisas que buscam estudar as práticas dos professores através das fontes orais, dando voz a esses mestres para que eles contem suas experiências. Um dos pressupostos teóricos dessas pesquisas sobre memória e ensino é a idéia de que a maneira de o professor atuar em sala não depende apenas da disciplina e da metodologia de ensino, mas também das vivências que teve ao longo da vida. Cada professor tem sua maneira própria de ensinar, a qual tem profunda relação com sua história pessoal de vida. (KENSKI, [199-], p. 107)

Devido a isso, cada um irá trabalhar os conteúdos, estabelecidos pelo currículo oficial, da sua maneira. Assim, a seleção dos conteúdos não termina nas decisões governamentais, mas tem sua continuidade dentro do cotidiano da sala de aula, onde realmente o currículo toma existência. "O professor é detentor de um conhecimento, mas de um conhecimento que não é interpretado na neutralidade. Sua história pessoal, suas crenças e suas representações atuam 
como filtros interpretativos que dão direção e sentido ao conhecimento que transmite." (PEDRA, 1997, p. 84)

Ivor GOODSON (1995) afirma que é importante estudar as histórias de vida dos professores para poder analisar melhor o currículo e a escolaridade. Para ele, a investigação educacional precisa ser reconceitualizada, dando a chance para a voz do professor ser ouvida. "Ouvir a voz do professor devia ensinar-nos que o autobiográfico, a vida, é de grande interesse quando os professores falam do seu trabalho.[...] O que considero surpreendente, se não francamente injusto, é que durante tanto tempo os investigadores tenham considerado as narrativas dos professores como dados irrelevantes." (GOODSON, 1995, p. 71)

Essa é uma afirmação que contribui para reiterar a importância da opção metodológica de dar voz a alguns professores que lecionaram nos anos setenta. Com relação à pesquisa realizada, o resgate da memória desses professores possibilitou o conhecimento das práticas educativas da época estudada, ajudando a entender como era o ensino daquele período.

A utilização das fontes orais foi feita mediante entrevistas com sete professoras que lecionaram a disciplina de Estudos Sociais durante a década de setenta. O critério básico para a escolha desses professores foi o seguinte: ter lecionado Estudos Sociais em turmas da 5. à 8 . $^{\text {a }}$ série, na década de setenta, na rede estadual de ensino paranaense, em Curitiba ou Região Metropolitana.

Das sete professoras que foram entrevistadas, duas são formadas em História, uma em História e Geografia, uma em Geografia, duas em Ciências Sociais e uma em Estudos Sociais. Todas essas professoras lecionaram a disciplina de Estudos Sociais nos anos setenta, em Curitiba ou em São José dos Pinhais, município da Região Metropolitana de Curitiba.

Não foi trabalhada a idéia de que essas sete professoras sejam uma amostra do magistério do período, mas sim que cada uma tem sua própria história de vida e seu papel dentro do ensino dos anos setenta. Cada uma escolheu o magistério por uma determinada razão, trabalhou de uma determinada maneira, aceitou ou não as reformas do período e, hoje, depois de se aposentar, tem determinada visão do período em que lecionou. São depoimentos que contribuem para esclarecer, do ponto de vista do professor, o sentido das reformas e a situação do ensino de História na década de setenta.

Elas se tornaram professoras por imposição dos pais, por pura falta de opção, por acaso ou por escolha própria, portanto foram fatores aleatórios que as levaram a essa escolha profissional. Suas histórias de vida são diferentes, vieram de locais diferentes, tiveram inclusive formação acadêmica diferente, 
porém todas elas acabaram se tornando professoras da rede paranaense de ensino e lecionaram Estudos Sociais com turmas da 5. à 8. ${ }^{a}$ série nos anos setenta.

Portanto, são pessoas que viveram suas experiências profissionais relativamente no mesmo período e, assim, suas memórias acabam sendo a memória do grupo social em que viveram. Através do resgate desses testemunhos orais, foi possível perceber não apenas como os conteúdos de História foram propostos pelas reformas de ensino e pelo currículo, mas, por outro lado, como eles foram compreendidos na prática da sala de aula.

A pergunta que se colocou foi: como se dava a prática dos professores em sala de aula, já que estavam atuando num momento em que o currículo trazia uma visão da História Oficial?

\section{Memória e ensino de História}

Analisando o conjunto dos relatos das professoras, pode-se observar, em relação ao percurso profissional do início de suas carreiras, algumas características comuns. A maioria delas iniciou a sua formação fazendo o antigo curso Normal e, antes de trabalharem com turmas da $5 .^{\mathrm{a}}$ à $8 .^{\mathrm{a}}$ série, lecionaram nas séries iniciais.

Outra característica comum nos relatos é que o percurso inicial dessas professoras é geralmente marcado por uma grande mobilidade, já que ocorre uma constante mudança de escolas no início das suas carreiras. Muitas delas, inclusive, chegaram a lecionar em diversos municípios do Paraná, pois naquela época - final dos anos sessenta - o professor deveria ir para o local onde havia vagas e esse local poderia ser em qualquer cidade do Estado.

Portanto, há várias características comuns no início da carreira dessas professoras que as identificam, incluindo aqui o fato delas terem vindo de cidades do interior do Paraná ou da Região Metropolitana de Curitiba, a maioria com o objetivo de estudar na capital. Pode-se dizer que há entre elas uma história bastante próxima. Porém, os caminhos que elas seguiram, dentro da própria profissão, acabaram sendo diferentes.

Assim, cada professora teve um percurso próprio dentro de suas 
carreiras, algumas permaneceram durante toda a sua vida profissional apenas em sala de aula e outras acabaram exercendo cargos administrativos dentro das escolas.

\section{1-1976: o ensino de Estudos Sociais sem currículo oficial}

Já foi visto que, com a implantação da Lei n. ${ }^{\circ} 5692 / 71$, o ensino de História ficou atrelado à área de Estudos Sociais. Assim, o professor de Estudos Sociais, a partir desse momento, teria que dar aulas de História, Geografia, OSPB e EMC, fosse ele historiador, geógrafo ou de outra formação na área das Ciências Humanas, como Sociologia, Filosofia ou mesmo Estudos Sociais.

Portanto, nesse momento histórico, a História perdeu seu espaço como disciplina escolar da 5. a 8..$^{\mathrm{a}}$ série. Assim, com a implantação dos Estudos Sociais e o fato de o professor ter que lecionar disciplinas para as quais ele não estava preparado, acabou se gerando um descontentamento entre as professoras:

Quando terminei a faculdade de História, entrou a Lei 5692/71. Com isso, quem era historiador, quem era geógrafo, tinha que dar aulas de Estudos Sociais da 5. à 8. a série e eu me negava. Em 1973, quando teve início a implantação da Lei 5692/71 em São José dos Pinhais, eu já

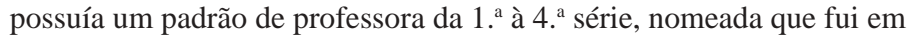
1970. Com essas vinte horas, trabalhava como coordenadora pedagógica da Escola Estadual Olavo Bilac. Nesse mesmo ano, além das minhas aulas no noturno, dentro da Lei 4024/61, no Colégio Estadual Dr. Roque Vernalha, trabalhei com uma turma da 5. ${ }^{\mathrm{a}}$ série do novo Estudos Sociais. Alguns professores gostaram porque o mesmo professor dava cinco aulas semanais na mesma turma: História, Geografia e Moral e Cívica. Mas eu não quis, não tinha nada a ver e eu optei por ficar com o 2..$^{\circ}$ grau, porque aí eu só dava aula de História. Aí eu fui ficando no $2 .^{\circ}$ grau, longe dos Estudos Sociais. (M. A.)

Nessa fala, há uma resistência à implantação dos Estudos Sociais e uma crítica à forma como a área foi implantada, a partir de uma imposição, 
sem discussões com os professores. O professor era obrigado a trabalhar com disciplinas que ele não estava preparado para lecionar e nem tinha uma formação teórica adequada. A alternativa que a professora M. A. encontrou para não trabalhar com os Estudos Sociais foi optar por lecionar apenas com turmas do então $2 .^{\circ}$ grau, no qual a História ainda aparecia enquanto disciplina.

A implantação dos Estudos Sociais não foi fácil, porque os professores que haviam feito concurso de História ou Geografia haviam se especializado mais naquela disciplina e tinham que lecionar a outra também. Por exemplo, eu fiz o concurso de História, me especializei em História e tinha que estudar Geografia e não gostava de Geografia. Então não foi fácil e não foi correto. Porque eu não tinha nem condições, eu mesma me avaliava e eu mesma não me sentia segura para lecionar Geografia. Então não foi fácil e acho que não foi correta essa decisão, porque na faculdade a gente teve um conhecimento geral, mas, ao fazer o concurso, a gente se especializou numa determinada disciplina e quando veio essa imposição, porque foi uma imposição, porque sempre vem de cima, aí então a gente foi obrigada a estudar, mas quando você entrava em sala de aula automaticamente você dava muito mais a matéria de que você gostava e em que se sentia bem, do que a outra, em que você se sentia mais insegura. Eu sempre gostei mais de História. (Diva)

Em 1972, houve a mudança da lei e quem dava aula e era concursado em História ou Geografia tinha que dar aula de Estudos Sociais. Nós tivemos que fazer um curso no mês de janeiro inteiro, quatro horas de manhã e quatro à tarde, para nos prepararmos para darmos Estudos Sociais. (Helena)

Com a criação dos Estudos Sociais, surge o professor polivalente, aquele que deveria saber um pouco de cada uma das disciplinas da área. São criados então os cursos de licenciatura curta em Estudos Sociais, os quais espalharamse rapidamente pelo país.

Eu sei que, logo em seguida à implantação da 5692, eu fui tirar a carteirinha do MEC e eles me deram autorização para lecionar História do $1 .^{\circ}$ e $2 .^{\circ}$ grau, OSPB e Estudos Sociais. Mas eles chegaram a dizer: você deveria fazer Estudos Sociais. Parecia que você era meio 
marginalizada. Eu nunca fui barrada para dar aula de Estudos Sociais, porque tinha o registro do MEC. Mas eu não sei dizer se professores que se formaram em História depois de mim, por exemplo, receberam o registro do MEC em Estudos Sociais.

Só que, como eu disse, de repente a gente passou a ser, no final dos anos setenta, uma minoria, nós, historiadores e geógrafos, éramos uma minoria. A PUC formava levas de professores em Estudos Sociais, professores da $1 .{ }^{\mathrm{a}}$ à $4 .^{\mathrm{a}}$. Com uma reforma no quadro do magistério do Estado, eram promovidos e ganhavam mais, tendo um curso universitário. Então eles faziam Estudos Sociais e aí, além de dar aula da 1. à 4. ${ }^{\text {a }}$, eles tinham direito de lecionar Estudos Sociais da 5. à 8. ${ }^{a}$ série. O que havia de professor para dar aula de Estudos Sociais era incrível. (M. A.)

Observa-se então que, com a criação dos cursos de Estudos Sociais, formavam-se, a cada ano, inúmeros novos professores com licenciatura curta, os quais acabavam dividindo espaço com os historiadores e geógrafos nas aulas de Estudos Sociais.

Assim, o que ocorreu em grande parte das escolas foi que a área de Estudos Sociais se manteve em termos oficiais, porém muitas vezes os professores, dentro de suas salas de aula, trabalharam com a História e a Geografia de maneira autônoma, sem a interligação que a reforma pretendia.

Após o início do trabalho com Estudos Sociais, cada escola elaborava o seu próprio planejamento de ensino, cuidando para fazer a integração entre História, Geografia, OSPB e EMC. Porém, não havia ainda um currículo oficial de Estudos Sociais que auxiliasse o trabalho do professor. O currículo de Estudos Sociais só foi publicado no Paraná em 1976.

Portanto, o que havia era apenas uma orientação para que se trabalhasse de forma integrada com História e Geografia, porém não havia nenhuma orientação de como se trabalhar efetivamente com os conteúdos de História e Geografia dessa forma interligada, como Estudos Sociais. As escolas elaboravam seus próprios planejamentos segundo o que os professores achavam que era o correto, porém sem um currículo oficial.

No período anterior à implantação do currículo de Estudos Sociais, o que os professores tinham de orientação eram os cursos realizados no Centro de Treinamento do Magistério do Estado do Paraná (Cetepar).

É como eu te disse, havia, por exemplo, uma reunião com cinqüenta professores no Cetepar, meia dúzia questionava. E aí era rotulado de 
briguento, radical, de oposição. A maioria calava a boca, ficava quieta. E, calou a boca, consentiu. Essa questão do pioneirismo tem fundamento, porque realmente foi assim. Eu lembro que sempre foi falado isso. Graças ao Ney Braga, que foi Ministro da Educação por um tempão [no período do presidente Ernesto Geisel]. Eu lembro que o Paraná recebia grandes recursos para o Cetepar, era muito dinheiro. Esses currículos eram rodados aos milhares e qualquer proposta da $1 .^{\mathrm{a}}$ à $4 .^{\mathrm{a}}$ série, os professores ficavam às vezes uma semana, ou até dez dias discutindo. Mas era assim: as técnicas de ensino, a técnica de formar um painel integrado, como trabalhar com mapas e globos. A grande preocupação dos cursos do Cetepar era passar técnicas de como trabalhar, nada de discussões de conteúdo. (M. A.)

Com o Cetepar e as verbas suntuosas se criou um centro de treinamento para o professor, daí vinha tudo com apostila. Eu participei de alguns cursos, mas só por ir e ter o certificado. Aproveitamento eu não tive. $\mathrm{O}$ que eu aproveitava era em termos de troca de experiências com os outros professores que também estavam ali. Em termos de conteúdo, a pessoa que repassava era muito fraca. Sempre foi assim. (N.)

Portanto, embora os cursos do Cetepar fossem praticamente o único meio de orientação sobre a reforma que os professores possuíam, na verdade não tratavam de questões referentes aos conteúdos propriamente ditos, mas se limitavam a técnicas de ensino e informações sobre a legislação do período. Por isso, até a publicação do novo currículo de Estudos Sociais, cada escola trabalhava os conteúdos a sua maneira, pois não havia uma orientação do Estado em relação a eles.

\section{O ensino de História e o currículo de Estudos Sociais de 1976}

Em 1976, foi publicado o currículo de Estudos Sociais do Estado do Paraná. Porém, o novo currículo de Estudos Sociais, elaborado após as reformas de ensino da década de setenta, só foi publicado em 1976, pela Secretaria da Educação e Cultura, e começou a ser implantado nas escolas apenas em 1978. Essa implantação foi gradativa. Em 1978, seria a 5. ${ }^{a}$ série, em 1979, a 6. ${ }^{a}$, em 1980, a 7. ${ }^{a}$ e, em 1981, a 8. ${ }^{\text {a }}$ série. 


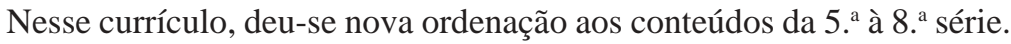
Por exemplo, o conteúdo da 5. ${ }^{\mathrm{a}}$ série começava com História Antiga e não História do Brasil, como era feito anteriormente.

Nos relatos das professoras, há críticas à forma como esse currículo foi implantado no Paraná. Realmente não houve discussões com os professores, ele foi imposto e mudou, sem maiores explicações, a ordenação dos conteúdos de História da 5. à 8. ${ }^{a}$ série. Essa nova ordenação parece ter sido a maior dificuldade que os professores encontraram no novo currículo oficial.

Isso aparenta que, embora existisse uma equipe encarregada de elaborar o novo currículo de Estudos Sociais, não foram feitas maiores discussões sobre essa elaboração, nem muito menos consultas aos professores em busca de propostas ou opiniões.

Embora teoricamente fosse obrigatória a utilização desse novo currículo, percebe-se, pelos relatos das professoras, que na prática não era bem assim:

O currículo foi utilizado só meio por cima. Não dava certo. Eu acho que essa coisa de Estudos Sociais nunca funcionou direito. E eu sou sincera, nos anos em que eu trabalhei com Estudos Sociais, minha tendência sempre era de dar mais História do que Geografia, eu gostava mais, não entendia aquela coisa de Geografia. Tinha que estudar que nem louca. Você não tinha a fundamentação teórica que deveria ter. E o professor formado em Estudos Sociais não tinha a fundamentação teórica que deveria ter, tanto na História como na Geografia. Eu lembro que diziam que o professor de licenciatura curta também era um professor curto, porque não tinha a formação adequada. (M. A.)

Sobre os cursos que eram dados no Cetepar, após a implantação do novo currículo, M. A. afirma o seguinte:

Quando chegou o momento de implantar esse novo currículo, o professor já estava meio perdido. Os questionamentos foram pouquíssimos. Eu lembro que quando fui fazer o curso de reciclagem para o novo currículo, acho que tinha mais de cem professores. A grande maioria ficou quieta, é para aceitar e pronto. Não houve discussões. Tudo foi pacífico. Isso é o que a gente aprendia nos cursos do Cetepar: o professor tinha que ter o domínio cognitivo, afetivo e psicomotor. Eles gastavam dias falando nisso... como que se elabora um objetivo com domínio cognitivo? Ele 
contempla o conhecimento. Que verbo vou usar? O curso era por aí... então vai usar o verbo identificar. Você passava os cursos do Cetepar fazendo isso. Eu não lembro de eles terem dito: agora vamos estudar a questão da emancipação política da América Latina. O curso era para estudar os objetivos específicos, lavagem cerebral... era "reciclar" os

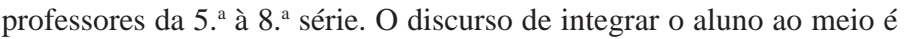
um projeto da ditadura militar, é um projeto da lei da época. Todo o discurso era em torno da boa sociedade, no campo você vive harmonicamente, a família exemplar, a família papai e mamãe, aquela coisa toda. No programa de EMC tinha muito disso, de viver harmonicamente, numa boa, todo mundo vivendo feliz. Nada de ruim existia dentro da sociedade brasileira. (M.A.)

Pelo depoimento dos professores, parece que o grande entrave desse novo currículo foi o fato de ter de trabalhar com História Geral na 5. a série.

Você veja, o que se fazia da 1 . à $^{\mathrm{a}}$. $^{\mathrm{a}}$ série era a integração social. Eram pequenas pinceladas de História do Brasil, datas comemorativas, o Sete de Setembro, o nome do D. Pedro I, a data e algumas coisinhas assim. Aí você chega na 5. ${ }^{a}$ série e vai estudar Egito Antigo. O professor não sabia o que deveria contemplar de Egito, ele não era preparado. $\mathrm{O}$ professor acabava seguindo o livro didático. E era aquele livro do Proença, que era o único livro que seguia esse novo currículo. (M. A.)

Esse livro que a professora M. A. cita foi editado pelo Instituto Brasileiro de Edições Pedagógicas (IBEP) e se chamava Estudos Sociais - de acordo com as novas diretrizes curriculares do Estado do Paraná, do autor Antônio Carlos Proença. Ele foi escrito tendo como base o novo currículo de Estudos Sociais do Paraná. Uma das dificuldades de se trabalhar com o novo currículo estava na adoção do livro didático, pois a grande maioria dos livros da época trabalhavam com História do Brasil na 5. ${ }^{a}$ e $6 .^{a}$ série. Então esse livro do professor Proença foi muito utilizado nesse final dos anos setenta, porque era praticamente o único livro que seguia o conteúdo de acordo com o currículo do Paraná. 
O currículo era supermal dividido. $\mathrm{Na} 6{ }^{\mathrm{a}}$ série, o primeiro bimestre era Geografia e o restante era tudo História. O professor era bitolado no livro didático e este sempre trazia História do Brasil na 5. e 6 . $^{\mathrm{a}}$ série. A dificuldade durou até o momento em que foi editado o livro que seguia o conteúdo proposto pelo currículo básico. Cada unidade ou subunidade do livro correspondia ao proposto no currículo. Um grande número de escolas adotou essa coleção, mesmo sendo muito fraca, porque os professores achavam ótimo um livro que não desse trabalho. ( M. A.)

Embora a professora M. A. tenha ressaltado que havia uma obrigação de se utilizar esse currículo de 1976 nas escolas, outras professoras dizem que não chegaram a usá-lo.

Eu nunca trabalhei com História Antiga na 5. ${ }^{\text {a }}$ série. Como é que a criança iria sair do primário e já ia passar para a História Antiga sem conhecer suficientemente História do Brasil? Isso só foi adotado quando eu estudei, em 1949, em Castro. No período em que eu dei aula, eu nunca usei esse currículo. Só quando eu era estudante da 5. a série é que eu estudei História Antiga na 5. ${ }^{\mathrm{a}}$ série e até achei meio pesado. Eu tive História Geral na 5. ${ }^{\mathrm{a}}$ e na $6 .^{\mathrm{a}}$, o que acho um absurdo. Na 7. ${ }^{\mathrm{a}}$ e na $8 .^{\mathrm{a}}$ é que eu tive História do Brasil. (Laura)

Nós achávamos que era um assunto tão complexo falar sobre Roma, Egito para uma criança da $5 .{ }^{\text {a }}$ série. Nós, como professoras, achávamos isso impossível. No Cristo Rei, nós não seguimos esse currículo. (Diva)

Como houve escola que seguiu o currículo novo e outras não, houve problemas com os alunos que se transferiam de uma escola para outra:

Então era uma dificuldade, alguns colégios mantiveram os Estudos Sociais e outros não, alguns tinham Antiga na 5. ${ }^{\mathrm{a}}$ série e na outra escola era História do Brasil. Então isso tudo foi um revertério muito grande, principalmente para quem era transferido de um Estado para outro, e isso criou uma série de obstáculos imensos. Porque é muito bonito quando você reforma uma lei, no papel, na hora da prática é diferente. (Helena) 
Portanto, o currículo de Estudos Sociais de 1976 não foi adotado em todas as escolas e, mesmo onde foi, acabou ficando por pouco tempo. A partir de 1982, quando houve eleição para governador e José Richa foi eleito, passou a haver, segundo a professora M. A., uma maior liberdade para se trabalhar fora do currículo. Então, oficialmente o currículo continuou, mas na prática ele passou a ser ignorado e os professores passaram a trabalhar novamente no esquema anterior, com História do Brasil na 5. ${ }^{a}$ série.

Então, é possível observar que havia uma resistência ao currículo de Estudos Sociais, porém o ponto fundamental dessa resistência era o fato de se ter de trabalhar com História Geral na $5 .^{a}$ série. Não havia um questionamento em relação aos conteúdos em si, mas apenas à inversão da ordem de como trabalhá-los em cada série. Não há, por exemplo, uma crítica à forma como o currículo sugeria que se trabalhasse com o presente, sem questionamentos. Muito menos uma crítica ao porquê de a reforma ter criado os Estudos Sociais e, assim, ter esvaziado os conteúdos de História. Portanto, havia uma resistência, porém que não atacava as questões de fundo da reforma e das mudanças do ensino de História.

\section{Conclusão}

O que se conclui, pela reconstrução das memórias das professoras, é que a disciplina de Estudos Sociais era, na prática, trabalhada de forma separada, com História, Geografia e EMC. A única correlação existente era o fato de se trabalhar História do Brasil e Geografia do Brasil. Por um lado, questionava-se o currículo e trabalhava-se com História do Brasil ao invés de História Geral. Por outro, continuava-se trabalhando com História do Brasil como estava na organização curricular para a $7 .^{a}$ e $8 .^{a}$ série. Portanto, não era atacada a questão de fundo, em relação à proposta oficial de qual História deveria ser ensinada. Não há nenhum questionamento em relação a isso ou uma tentativa de se fazer um trabalho diferenciado, mais crítico com os alunos.

Já foi visto, no início deste artigo, que cada professor possui uma maneira própria de ensinar, a qual tem profunda ligação com a sua maneira de ser, com o seu "eu", com a sua história de vida. É na sala de aula que os conteúdos e o currículo realmente tomam existência. Segundo NÓVOA (1995, p. 16), 
[...] a resposta à questão, Por que é que fazemos o que fazemos na sala de aula?, obriga a evocar essa mistura de vontades, de gostos, de experiências, de acasos até, que foram consolidando gestos, rotinas, comportamentos com os quais nos identificamos como professores. Cada um tem o seu modo próprio de organizar as aulas, de se movimentar na sala, de se dirigir aos alunos, de utilizar os meios pedagógicos [...].

Alguns professores procuraram trabalhar os Estudos Sociais de forma conjunta, trabalhando com História e Geografia de forma interligada, porém a maioria parece ter trabalhado separadamente as duas disciplinas, embora oficialmente trabalhassem com Estudos Sociais.

Alguns professores utilizaram o novo currículo de Estudos Sociais, de 1976, e trabalharam com História Geral na 5. ${ }^{a}$ e $6 .{ }^{a}$ série. Já outros ignoraram esse currículo e continuaram a trabalhar com História do Brasil nessas séries, como no período anterior à implantação do currículo. Alguns professores faziam avaliações conjuntas de História e Geografia, outros aplicavam provas separadas para cada matéria. Alguns professores seguiam à risca os livros didáticos adotados pelas escolas, às vezes de Estudos Sociais, às vezes um para História e outro para Geografia. Outros procuraram buscar outras formas de trabalho, como o uso de textos diferentes, de diversos autores. Alguns faziam os tradicionais questionários e provas objetivas, outros tentaram fazer outras formas de avaliação, como trabalhos em grupo e questões dissertativas.

Cada professor trabalhou a seu modo, da maneira que achou que era a mais correta, dentro das suas possibilidades e das escolas onde lecionou. Tentaram superar a falta de orientação para o trabalho com disciplinas diferentes, para as quais muitas vezes eles não estavam preparados, e a imposição de uma reforma e de um currículo que foram feitos sem discussões com os próprios professores. Pelos relatos, percebe-se que, no que se refere à ordenação dos conteúdos, o currículo oficial de Estudos Sociais acabou sendo criticado e muitas vezes não aceito e nem utilizado nas escolas. Porém, muitas vezes os professores utilizavam livros didáticos que estavam muito próximos da proposta do governo. 


\section{REFERÊNCIAS}

BOSI, E. Memória e sociedade. São Paulo: T. A. Queiroz, 1983.

FONSECA, S. G. Ser professor no Brasil. São Paulo: Papirus, 1997.

GARRIDO, J. A. As fontes orais na pesquisa histórica: uma contribuição ao debate. Revista Brasileira de História. Memória, História e Historiografia, São Paulo, v. 13, n. 25/26, p. 33-55, set. 1992/ago. 1993.

GOODSON, I. F. Dar voz ao professor: as histórias de vida dos professores e o seu desenvolvimento profissional. In: NÓVOA, A. (Org.). Vidas de professores. 2. ed. Lisboa: Porto, 1995. p. 63-78.

HALBWACHS, M. A memória coletiva. São Paulo: Vértice, 1990.

HARTOG, F. A memória e o tempo. O Correio da Unesco, Rio de Janeiro, n. 5, p. 13-15, maio 1990.

KENSKI, V. M. Memória e prática docente. In: BRANDÃO, C. R. (Org.). As faces da memória. Campinas: Centro de Memória - Unicamp, [19-]. p. 101114.

LE GOFF, J. História e memória. Campinas: Unicamp, 1990.

MARSON, A. Reflexões sobre o procedimento histórico. In: SILVA, M. A. (Org.). Repensando a História. Rio de Janeiro: Marco Zero, 1984. p. 37-64.

MEIHY, J. C. S. B. História oral: um locus disciplinar federativo. In:

(Org.). (Re)introduzindo História oral no Brasil. São Paulo: Xamã, 1996. p. 48-55.

NÓVOA, A. Formação de professores e profissão docente. In: (Org.).

Os professores e a sua formação. Lisboa: Dom Quixote, 1992. p. 13- 33.

. Os professores e as histórias da sua vida. In: . (Org.). Vidas de professores. 2. ed. Lisboa: Porto, 1995. p. 11-30.

História da educação: perspectivas atuais. [S. 1.: s. n.], 1996.

PEDRA, J. A. Currículo, conhecimento e suas representações. São Paulo: Papirus, 1997.

POLLAK, M. Memória e identidade social. Estudos Históricos, Rio de Janeiro, v. 5, n. 10, p. 200-212, 1992. 